\title{
Sítio Arqueológico Tenda Pai Joaquim de Aruanda: Inserção na paisagem cultural e relações com os saberes tradicionais quilombolas do espinhaço meridional
}

\author{
Júlio Jader Costa ${ }^{1}$ \\ E-mail: jicpsi@hotmail.com
}

\begin{abstract}
Resumo: O sítio arqueológico localiza-se há mais de mil metros de altitude, no município de Conceição do Mato Dentro, em área circunscrita pelo distrito de Ouro Fino. Trata-se de um sítio ritual de Umbanda que permaneceu ativo entre meados e o fim do século $X X$, quando encerrou suas atividades devido ao falecimento de seu chefe de trabalhos: o curandeiro e médium de Umbanda Abel Matias de Souza. Sua posição espacial, encravada em encosta íngreme e de difícil acesso, contrasta com as teses antropológicas centradas na visibilidade urbana da Umbanda e com a suspensão de proibições/maior permissividade do culto no período em que esteve ativa. Tais questões conduzem ao objetivo geral da pesquisa: estudo sobre os processos de inserção da Tenda Pai Joaquim de Aruanda na Paisagem Cultural e suas relações com os conhecimentos tradicionais de quilombolas e do campesinato negro rural em terras altas do espinhaço meridional.
\end{abstract}

Palavras chave: paisagem cultural, espinhaço meridional, arqueologia colaborativa, conhecimentos tradicionais, Umbanda, campesinato negro rural.

\begin{abstract}
The archaeological site is located more than a thousand meters of altitude, in Conceição do Mato Dentro municipality in area enclosed by fine gold district.It is a ritual site of Umbanda which remained active between the middle and the end of the twentieth century, when closed down due to the death of its chief of work: the healer and medium Umbanda Abel Matias de Souza. Its spatial position, stuck in steep slope and difficult to access, in contrast to the anthropological thesis focused on urban visibility of Umbanda and the suspension bans / higher permittivity of worship in the period in which he was active. Such questions lead to the overall objective of the research: study on the integration processes of Father Joaquim Tent of Aruanda the Cultural Landscape and its relations with traditional maroon knowledge and rural black peasants in the highlands of southern ridge.

Key words: cultural landscape, southern ridge, collaborative archeology, traditional knowledge, Umbanda, rural black peasantry.

\footnotetext{
${ }^{1}$ Psicólogo Social, graduado pela UFMG (2003). Especialista em Políticas Públicas pelo Departamento de Ciências Políticas da mesma universidade (2006). Estudante de graduação, cursando 8o Período em Antropologia - Habilitação em Arqueologia pela UFMG (2012-2015). Experiência: a) Desenvolvimento de metodologias emancipatórias para fortalecimento institucional de povos e comunidades tradicionais, englobando ações de diagnóstico, mobilização, qualificação de demandas e de processos de formação/autogestão/ativação de grupos e potências afirmativas da diversidade cultural; b) Atualmente dedicando-se a estudos etnoarqueológicos sobre patrimônio material e imaterial associado à Diáspora Africana em terras altas do Espinhaço Meridional.
}

(C) Rev. Arqueologia Pública \begin{tabular}{l|l} 
Campinas, SP & v.9
\end{tabular} No.(11) p.63-71 suplemento 
Resumen: El sitio arqueológico se encuentra a más de mil metros de altitud, en el municipio de Conceição do Mato Dentro, en recinto cerrado con el distrito de Ouro Fino. Es un sitio ritual de Umbanda que permaneció activa entre el medio y el final del siglo XX, cuando se cerró debido a la muerte de su jefe de trabajo: el sanador y medianas Umbanda Abel Matias de Souza. Su posición en el espacio, atrapado en fuerte pendiente y de difícil acceso, en contraste con la tesis antropológica que se centró en la visibilidad urbana de Umbanda y las prohibiciones de suspensión / mayor permisividad de culto en el período en que estuvo activo. Estas preguntas conducen al objetivo general de la investigación: estudio sobre los procesos de integración de La Tienda Pai Joaquim de Aruanda em la paisaje cultural y sus relaciones con el conocimiento tradicional de los campesinos negros rurales en las tierras altas de la cresta sur.

Palabras clave: paisaje cultural, la cresta sur, arqueología de colaboración, conocimientos tradicionales, Umbanda, campesinado negro rural.

\section{Introdução}

O sítio arqueológico "Tenda Pai Joaquim de Aruanda" está localizado numa altitude de 1054 na Serra da Gurita, em área circunscrita pelo distrito de Ouro Fino (no município de Conceição do Mato Dentro). Trata-se de um sítio ritual de Umbanda, cujo processo de registro cartorial data de 16 de agosto de 1976, com a "Finalidade de estudar o espíritismo umbandista (culto afro brasileiro) e praticar a caridade de acordo com suas possiblidades." A tenda permaneceu em funcionamento até o final do século $X X$, quando encerrou as atividades devido ao falecimento de seu chefe de trabalhos: Abel Matias de Souza. Sua posição espacial contrasta com a origem urbana da Umbanda e com a suspensão de proibições/maior permissividade do culto umbandista no período em que esteve ativa.

A Tenda Pai Joaquim de Aruanda emergiu como objeto de interesse para a pesquisa científica no contexto de trabalhos de fortalecimento institucional da Comunidade Quilombola de Candeias, com a qual estabelece vizinhança. As referências à Tenda, descrita como local onde se realizavam curas e feitiços, ocorreram durante momento etnográfico que investigava elementos de ancestralidade e memória da comunidade. Segundo os relatos, o local era situado "duas léguas serra acima" (na direção do distrito de Ouro Fino) (...), "onde se falava uma língua estranha... língua de Umbanda" (...). Nas sessões realizadas na Tenda, Abel Matias de Souza era o "cavalo" que incorporava Pai Joaquim de Aruanda. Mas, para aquém do transe mediúnico, seu prestígio como curandeiro e profundo conhecedor das ervas e raízes do sertão extrapolavam as fronteiras da Tenda estas comunidades e atingiam áreas distantes da Serra do Espinhaço e até mesmo habitantes de Belo Horizonte e Brasília teriam recorrido 
aos seus trabalhos. Os relatos testemunham o grande carisma que afetava moradores das Comunidades de Candeias e Ouro Fino mais de uma década após sua morte.

Após o seu fechamento, na última década do século XX, a Tenda foi abandonada. No local está a estrutura de base. Adjacentes estão localizadas as estruturas da Casa de Abel Matias. Ambas eram feitas de adobe, madeira e pedras. No escopo dos estudos sobre sistemas de assentamentos associados à Diáspora Africana no Brasil, além das definições negativas que vinculam a localização dos sítios arqueológicos à variáveis de conflito social (opressão escravista seguida de resistência quilombola e repressão aos cultos de matriz africana), o estudo da paisagem cultural abre campo para uma definição positiva que resulte de variáveis ambientais (natureza), com os sistemas de crença e elementos da ciência tradicional dos quilombolas? b) Qual a relação da Tenda (sua localização) com os saberes associados à diáspora africana nas terras altas do espinhaço? c) É possível conferir pesos distintos às variáveis ambientais e de conflito social no tocante a escolha do lugar para assentamento da Tenda; d) $O$ que levou Abel Matias a assentar a Tenda naquele lugar específico? e) Enfim, considerando a invisibilidade de suas estruturas e vestígios, que contrastam com a intensa ressonância que reverbera nos relatos dos quilombolas de Candeias, quais as perspectivas abertas pelo estudo da Tenda para o desenvolvimento de uma arqueologia colaborativa e implicações sobre o conceito de patrimônio?

Tais questões conduzem ao objetivo geral da pesquisa: estudo sobre os processos de inserção da Tenda Pai Joaquim de Aruanda na Paisagem Cultural e suas relações com os sistemas de crença e com os saberes tradicionais associados à diáspora africana em terras altas do espinhaço meridional.

\section{Paisagem Cultural no Espinhaço Meridional}

Durante a fase de campo identificou-se que a região dos trabalhos estava completamente tomada pelo mato. A natureza é exuberante, pois o sítio localiza-se em um dos encaixes da vertente, sendo margeado por um curso de água cristalina que flui de nascentes localizadas à montante. $O$ sítio foi visitado durante o período de estiagem que atinge anualmente o espinhaço (agosto a novembro). A tarefa de visita-lo em períodos chuvosos certamente seria mais penosa, dado o aumento do volume das águas e rochas escorregadias. 
Explorando sua montante, atingimos cerca de 300 metros acima um grande platô, limitado a oeste por íngreme e gigantesca escarpa. A vegetação é exuberante, menção especial às espécies raras de orquídeas, bromélias e cactáceas. Dali de cima, é possível fruímos a beleza do lindo vale do Rio Parauninha e planície adjacente, localizados bem abaixo, mas que vão evoluindo para morros ondulados de cerca de 300 a 500 metros, entrecortados por cursos d'água e córregos que definem sua forma e que vão se elevando progressivamente até atingir cumes mais elevados ao fundo (exemplo: Pico do Breu), onde estão localizadas as cabeceiras limítrofes com a Bacia do São Francisco e que descem cortando a rocha até desaguarem no rio Paraúninha. Em alguns pontos, a vegetação é tão escassa, que é possível identificar o substrato quartizítico (rocha metamórfica) que sustenta o conjunto, marcando passagens entre os campos de altitude e os campos rupestres propriamente ditos.

À leste do platô, na direção oposta à escarpa e rumo à jusante do riacho, a feição do relevo é semelhante, podendo ser visualizado o vale de um outro rio, igualmente imponente: o Rio Santo Antônio. Mas, aqui a vertente é tomada por matas de encosta muito densas que recobrem quase completamente as ondulações, alcançando e confundindo-se com as matas de galeria. Todavia, esta vegetação vai se tornando menos densa e arbustiva na medida em que aproximamos nosso olhar dos terços médio e inferior da vertente, transitando entre matas de capão, campos rupestres, até se transformar em pasto coberto por braquiárias, já no sopé próximo ao rio principal.

O platô de onde realizamos a prospecção visual marca o cume de um maciço que se estende longitudinalmente para as direções norte e sul, dividindo os vales dos rio Paraúninha e Santo Antônio, sendo o primeiro afluente do segundo, mas ambos pertencentes a Bacia do Rio Doce. Partindo do platô, acompanhando lateralmente o curso seco do riacho rumo à jusante e atravessando a densa cobertura arborizada da galeria, o sítio pode ser localizado, já quase no início do terço médio da vertente, onde esta se aplaina e se alarga, formando uma espécie de Bacia que se estreita mais abaixo até deparar-se como uma barreira de bananeiras (apontadas nos estudos etnográficos como locais em que eram realizados trabalhos para Exú).

(C) Rev. Arqueologia Pública \begin{tabular}{l|l} 
Campinas, SP & v.9
\end{tabular}

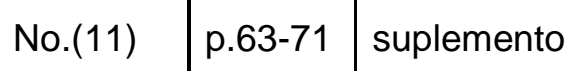
ISSN 2237-8294 
Abel Matias, exímio construtor, aproveitou esta configuração paisagística para criar uma barragem obliterando a passagem das águas que então formaram uma linda e resplandecente lagoa. Através de uma cava lateral de aproximadamente 1 metro de profundidade, a água que excedia o volume da lagoa era canalizada e drenada para a margem direita, até se bifurcar para alimentar dois Moinhos D’água localizados numa posição mais rebaixada do terreno. Além da eficiência econômica, os relatos apontam que tanto a lagoa quanto as quedas d'água dos moinhos teriam sido utilizados para deposição e descarte de artefatos votivos.

Atualmente, com a destruição (antrópica) da represa a água deixou de fluir para os moinhos, que abandonados dão lugar para estruturas depreciadas de adobe que contrastam a estrutura metálica de rodas e engrenagens e que indicam o local já foi muito produtivo. Com efeito, uma análise mais detalhada das unidades e áreas de influência doméstica registram que por ali se produziram alimentos variados, sendo maiores os vestígios de rocas de mandioca, milho. Também foram identificadas áreas específicas para o trabalho com barro, provavelmente adobe. Mas, são os vestígios de produção de telhas de barro que se destacam, sendo identificada uma verdadeira 'oficina de cacos' nas proximidades da lagoa, hoje inteiramente seca.

Inúmeras plantas sagradas e de poder para a Umbanda proliferam no sítio. Também estão localizadas estrategicamente árvores maiores que possuem relevância cosmológica para entidades da Umbanda, como Gameleira (associada aos trabalhos com os Pretos Velhos). Nos relatos etnográficos ficam evidentes os efeitos ressonantes das festas que foram realizadas no local, sendo destacados os elementos associados às colheitas e banquetes. $A$ festa mais vividamente rememorada na fala de alguns moradores de Candeias é a dos Erês, onde Abel Matias distribuía abundantemente para as crianças doces e rapaduras.

O Sítio arqueológico é ainda impactado pelas as queimadas (naturais e antrópicas), o desmatamento das encostas, dos topos de morro e das galerias, que contribuem para o carreamento de materiais durante as cheias. Entre o material transportado identificamos fragmentos e rochas das mais variadas dimensões, com destaque para os seixos rolados de quartzo, formidáveis para auxílio na fabricação de instrumentos líticos (percutores). Além do

(c) Rev. Arqueologia Pública \begin{tabular}{l|l} 
Campinas, SP & v.9
\end{tabular} \begin{tabular}{|l|l|l|} 
No.(11) & p.63-71 & suplemento
\end{tabular} ISSN 2237-8294 
transporte hidráulico, os materiais transportados pelo vento contribuem para a deposição arenosa, principalmente de arenito e quartzito.

Todavia, entre os processos que vem contribuindo para a (de) deformação do registro arqueológico merece especial atenção o "fechamento da Tenda", isto é, ritual de limpeza da área, conduzido por agente especializado (líder religioso e médium da Umbanda). O processo incluiu o resgate dos artefatos rituais mais importantes e a destinação de sua guarda para a Federação Espírita Umbandista de Minas Gerais e para outras casas (terreiros e tendas) espelhados pelo estado de Minas Gerais. Mas, nem todos os artefatos foram resgatados. $\mathrm{Na}$ prospecção feita pelo autor, por exemplo, foi identificada uma grande gamela possivelmente utilizada para maceração de ervas.

Sob a perspectiva da arqueologia colaborativa, a ressonância da Tenda tanto entre os moradores da comunidade quilombola de Candeias quanto entre os adeptos atuais vem justificando os esforços para a preservação do patrimônio remanescente, incluindo elementos da paisagem cultural.

\section{Resultados parciais}

A etnografia revelou que, a mãe de Abel Matias descendia de africanos escravizados e é referida como alguém que detinha conhecimento. Todavia, os fundamentos para o assentamento da tenda teriam sido obtidos em uma longa estadia que Abel Matias teria passado na região norte, quando de sua juventude.

\subsection{Identificação de perspectivas cosmológicas ou sistemas de crença}

Então a questão que se colocou incialmente para a pesquisa refere-se à possível existência de perspectivas cosmológicas ou sistemas de crença da população local que teriam contribuído para consolidação e expansão do culto na Tenda pai Joaquim de Aruanda. Neste momento, estão sendo fichados as fontes secundárias da historiografia que indicam apresenta uma riqueza de dados quantitativos e qualitativos (casuística) que mostram que apesar de serem proscritas oficialmente, as práticas mágicas de curandeirismo envolvendo plantas sagradas e outros feitiços realizados por negros eram amplamente disseminada em Conceição do Mato Dentro durante os séculos XVII e XVIII. Estes autores e sistematização dos dados serão apresentados detalhadamente na monografia.

3.2. Etnografia dos Quintais - O estudo dos quintais revelou tem revelado um profundo conhecimento dos quilombolas e camponeses negros no tocante ao cultivo de plantas com 
valor medicinal. Alguns raizeiros relatam ter bebido na fonte de Abel Matias e destacam a eficiência de suas garrafadas.

3.3. Inventário dos artefatos resgatados - até o presente momento, o inventário dos artefatos resgatados durante o processo de fechamento e limpeza da tenda, alguns dos quais do ínício do século XX, associado aos dados etnográficos que galgaram êxito na recuperação de alguns pontos cantados, permitem afirmar que a Tenda de Umbanda praticava rituais da Linha Cruzada, sendo esta informação completamente ausente em seus estatutos constituintes.

3.4. Caminho de tropas: foram tomados os pontos de georeferenciamento de todo o sítio e estruturas, incluindo os caminhos de tropas. Identificou-se que a tenda se localizava num ponto de convergência de tropas no entroncamento do único caminho que levava da Comunidade de Candeias para a sede do munícipio de Conceição do Mato Dentro, sendo o sítio local importante de pouso, descanso e refrego para a viagem de mais de trinta quilomêtros. Descobriu-se que a construção de uma nova estrada mais curta pelo vale rebaixado do Paraúninha, na década de noventa do século $\mathrm{XX}$, com dimensões suficientes para suportar o trânsito de automotores, pode ter exercido influência para o abandono do caminho de tropas, levando em fim ao seu fechamento. A hipótese atual de trabalho consiste justamente em aprofundar o estudo desta relação;

3.5. Projeto de Memória: Com o declínio da Tenda, Abel Matias teria recebido autorização de seus guias espirituais para assentar uma Igreja Católica no sopé da vertente do lado do vale do Rio Santo Antônio (distrito de Ouro Fino). Em seu altar entalhou em madeiras pontos riscados da Umbanda e plantou plantas sagradas e de poder da Umbanda em seu entorno, erigindo-se assim um projeto de memória - A Igreja Nossa Senhora Aparecida (abaixo).

\begin{tabular}{|l|l|l|l|l|l|l}
\hline ( Rev. Arqueologia Pública & Campinas, SP & v.9 & No.(11) & p.63-71 & suplemento & ISSN 2237-8294 \\
\hline
\end{tabular}




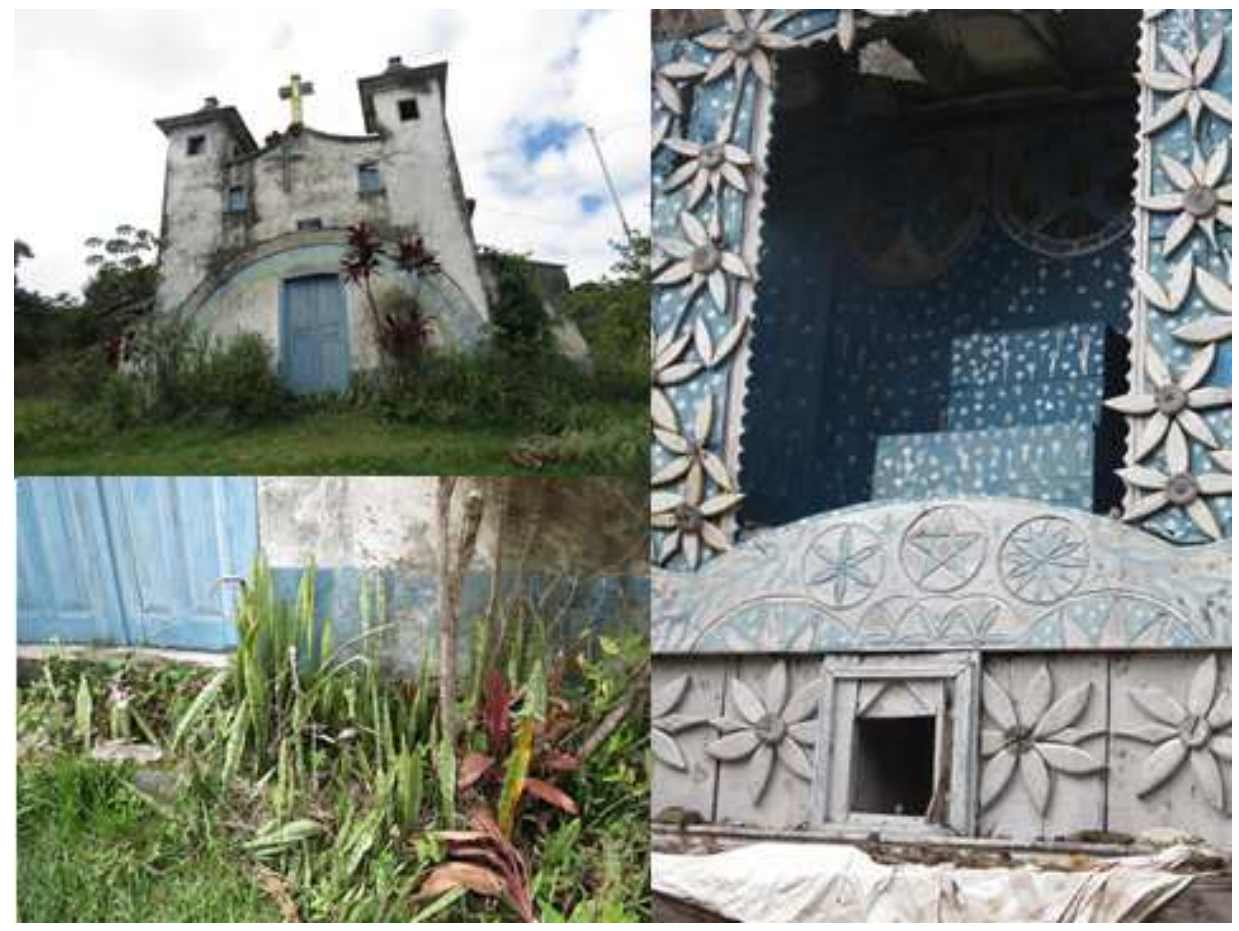

\begin{tabular}{|l|l|l|l|} 
v.9 & No.(11) & p.63-71 & suplemento \\
\hline
\end{tabular}


